\title{
Analysis of Mobile App Revenue Models Used in the Most Popular Games of the Tower Defense Genre on Google Play
}

\author{
Michael Groeschel ${ }^{1, *}$, Tim Schäfer ${ }^{2}$ \\ ${ }^{1,2}$ Mannheim University of Applied Sciences \\ Germany \\ ${ }^{*}$ Corresponding author's email: m.groeschel [AT] hs-mannheim.de
}

\begin{abstract}
This paper analyzes the revenue models of the most popular games of the Tower Defense genre on Google Play. A special look is taken at the quantitative distribution of the app sale model and the free model in terms of quality and download numbers. Additionally, this paper considers the qualitative implementation of the "free" model in the most popular games. First, the usual revenue models of mobile apps will be discussed and then the Tower Defense genre will be explained. Following that, the quantitative distribution of revenue models and an analysis of the most popular apps' respective revenue models will be addressed. The analysis also identifies and explains two modifications of established revenue models. The most popular revenue model for mobile apps in the Tower Defense genre are in-app purchases. This distinguishes the genre from many other genres and games. A wide range of Tower Defense games utilizes the revenue models app sale and free. It becomes apparent that revenue models for mobile apps must be analyzed and considered specifically for their respective sector, and that no single promising revenue model for apps exists.
\end{abstract}

Keywords— revenue model, business model, mobile apps, Google Play, mobile games

\section{INTRODUCTION}

In 2015, the market for mobile applications in Germany exceeded the one-billion-euro mark in revenue. Due to the increasing use of mobile devices and the expansion of broadband network the market is expected to continue to grow (refer to the forecast by [3]). The market is therefore very competitive and only a few mobile applications can become financially successful (see [12], p. 10). This makes it even more important to analyze the given market before developing a mobile application and to find a suitable revenue model for the respective mobile application (see [13], p. 147 and [14]).

This article analyzes the mobile app market for Tower Defense games with special regard to the revenue models used for the most popular ones. The aim is to gain insight into the revenue models practiced in a specific market. In addition, this paper attempts working out how the revenue models can be cleverly combined to maximize revenues. Games are generally well suited for such analyses, as they are both very popular and commercially promising (see [6]).

The next chapter differentiates between the basic concepts of revenue model and business model. In addition to an overview of the most common marketplaces for mobile apps, the most common revenue models for this kind of software are explained. Afterwards, an introduction to the basic features of Tower Defense games is given in order to identify possible starting points for a revenue model. The semi-automatically collected data on free and paid games of the genre in question is analyzed based on these principles. On the one hand this is done quantitatively, and on the other hand the implementation of the revenue models is qualitatively examined on the basis of several concrete examples that focus on the analysis of free games. The article finishes with a conclusion.

\section{REVENUE MODELS OF MOBILE APPS}

\subsection{Definition and distinction of the terms "revenue model" and "business model"}

Depending on the subject - consulting, research, teaching, etc. - the definitions and uses of the terms "revenue model" and "business model" differ accordingly [10]. The revenue model is typically only one part of the business model. According to Gassmann et al., revenue mechanics are one of four elements of the business model (see [15], pp. 6-7), in addition to customers, the value proposition and the value chain. In addition to the cost structure, the question of how revenues are generated is of central importance. Since most companies have several sources of income, the revenue model describes all - possibly different - sources of a company's income and considers their volume and distribution. 
The business model canvas, which is frequently used to design business models, considers income streams as one of nine elements in the representation of the business model (see [18]).

Mobile apps, therefore, have a revenue model in relation to the above definition, which may consist of several sources of income. Some sources of income allow a direct monetary remuneration and others an indirect one. This difference is discussed in more detail in topic 2.3. Ultimately, the revenue model is part of the business model of its respective company. In addition, mobile applications can also exist without a revenue or business model.

\subsection{Mobile app marketplaces}

There are several marketplaces to buy and download mobile applications from [16]. After the consolidation of the mobile platform ecosystems and the insignificance of the marketplaces BlackBerry World and Windows Phone Store, the dominant offers of Google (Google Play) and Apple (Appstore) remain. According to [4], more than 2.5 million apps are available on Google Play, of which 4.8\% are paid [5]. On the Apple Appstore, on the other hand, 10.7\% of apps have a fee [1]. This paper only evaluates data from Google Play; thus the results cannot be applied to Apple's Appstore without further scrutiny.

\subsection{Current revenue models for mobile apps}

While many authors have categorized apps as paid or financed by advertising, Dörndorfer and Seel have developed the broadest catalog of 14 revenue models (see [12] and [13]). Figure 1 provides an overview of the revenue models identified by the authors mentioned above. The revenue models that play an obvious role in the empirical study are briefly described below. From an external point of view, it is not possible to check whether other revenue models such as data gathering are also implemented as these are not transparent to the end user.

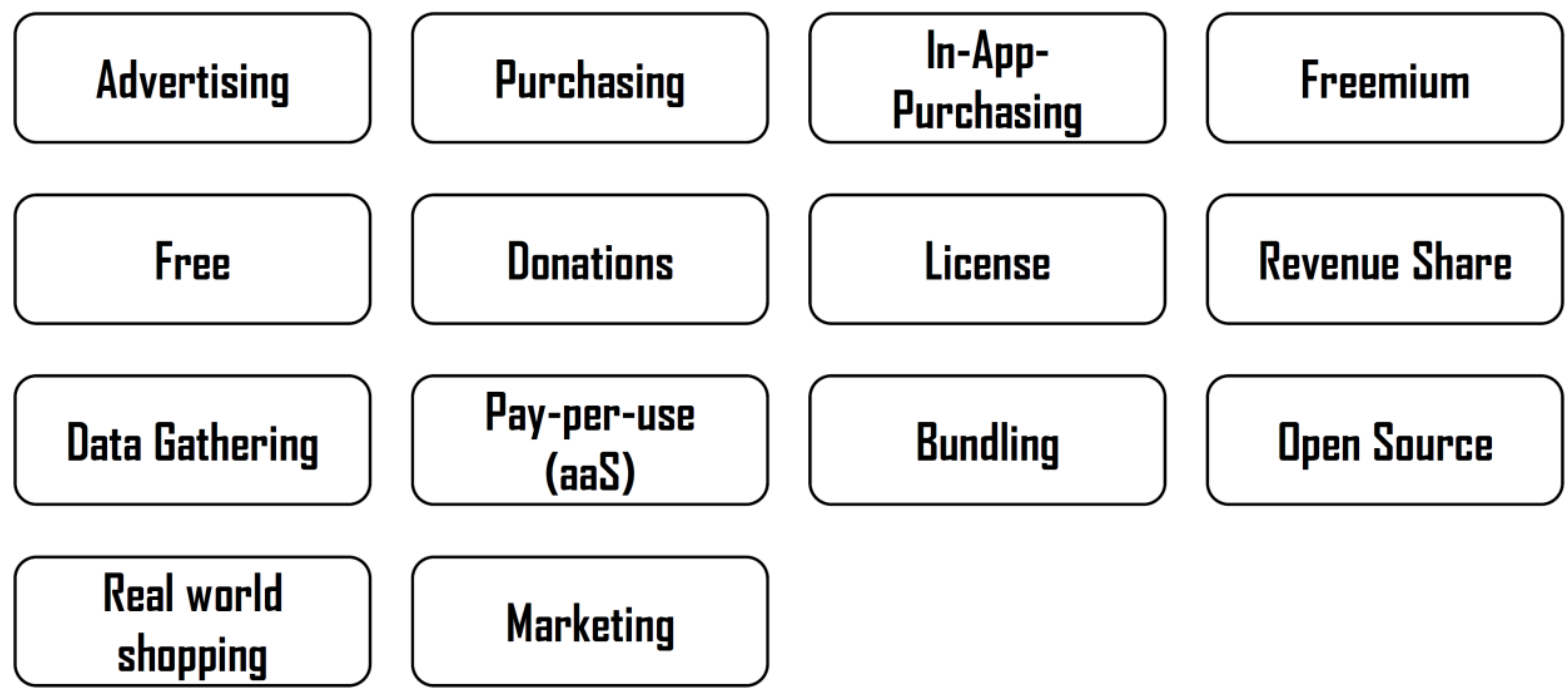

Figure 1: Revenue models for mobile apps (c.f. [14], p. 256)

Purchasing (App sale): The sale of a mobile application is a popular revenue model. Mobile applications are usually purchased by people between the ages of 25 and 34 on the official store site. This revenue model is widely accepted and is also combined with in-app purchases and the free model. However, combinations with this revenue model should always be considered with caution, as customers often expect that no further payments are necessary to use all features of a game after a purchase. It should be considered, that with this revenue model the store receives part of the revenue as it provides the marketplace. Furthermore, some countries mandate additional VAT fees to be paid (see [13], p. 151).

In-app purchases: With a distribution rate of $99 \%$, in-app purchases are the most popular revenue model for mobile applications among the top 200 apps in Apple's Appstore (see [13], p. 151). In this revenue model mobile applications are generally offered free of charge. Later, virtual goods can be purchased commercially. This enables better distribution on the overall market, as the hurdle to download the application is lower. This model is accepted by end-users and enables the provider to generate a steady stream of revenue. In-app purchases also cleverly exploit psychological aspects (see [7]). This model usually reaches people aged about 25 years and younger (see [13], p. 151).

In-app advertising: In this model, advertising is displayed in the running application. The advertising can be obtained from various third-party providers. This model is popular because, initially, all user groups remain relevant. In addition, an application is monetized directly, there are no direct costs for the user and the distribution of the application is not 
prevented by the hurdle of paying upfront. However, a high number of ads is necessary to make a profit, which can also lead dubious providers to commit Mobile Ad Fraud. In the case of manipulated apps, simulated clicks on advertising elements generate revenue through supposedly successful advertising, even though the clicks are automated on often invisible advertising elements within the app. Mobile Ad Fraud is particularly common in games (see [9] and [2], p. 22). Furthermore, advertising is often perceived as annoying (see [13], p. 152).

Free: An application is free if it's possible to download and use it for free without advertising or other disadvantages. With this model all user groups can be reached. This model represents an indirect revenue model, since the profit is not directly measurable monetarily. Applications with such a model are often used to market another product or to add functions to another product: e.g. a sound system with a suitable app. This model is often combined with other models to cover development costs (see [13], p. 152).

Freemium: There are two versions of freemium, a portmanteau of free and premium, in the Appstore. The free version enables the user to test the app. App providers hope that convinced users will purchase the paid version, which offers more features, and thereby generate income. The free version serves as advertisement for the paid application. In each individual case it must be clarified what serves as distinguishing features between both versions.

\section{THE TOWER DEFENSE GENRE}

The type of the Tower Defense genre described in this paper is based on the genre described in [8]. The Tower Defense genre emerged during the time of Flash-Games. It belongs to the category of strategy games and is still a popular and simple strategy game today. The player organizes units, classically these are the eponymous towers, which he or she must place on the game field and pay through a game-specific monetary system. Towers behave defensively and must defend their own area against enemies. Opponents are aggressive, can attack the towers in some variants of the genre, and aim to reach the end of the map that represents the playing field after they appear at the beginning of the map. The path from beginning to end is either pre-defined or can be influenced by the player by building towers. In the simplest case the map starts on the right side of the screen and ends on the left side. The player loses one life if the opponents reach the end of the map. If the opponent is eliminated by one of the towers, however, the player receives a reward. The player influences the game by buying, selling, placing and upgrading the towers. As the game progresses, the opponents become stronger and the player is encouraged to further populate the map with towers. Although there are many different forms of the genre, the following basic elements can be identified in each Tower Defense game (see [8] pp. 1085-1087).

- Map: The map provides the player with the basic layout. Towers can be placed at designated places and opponents can cross the map through designated paths. The map is usually static for each level.

- Towers: Towers are available in different variations, with different characteristics and special features. Many games focus on versatile characteristics of different towers. As mentioned above, towers can attack enemies as soon as they are within a specific range.

- Opponents: Opponents, like towers, exist in many different variations with different characteristics and special effects. Usually, at the end of a level a boss opponent must be defeated. A boss opponent is an opponent that is characterized by a particularly high resistance against the towers and is therefore harder to defeat.

- Reward system: The reward system of a Tower Defense game is its most important feature. Only by properly managing resources can the player be successful in the game. Building towers, upgrading them and losing life points usually means losing points. Defeating enemies means gaining points. Most games reset the points for each level to an initial amount.

Figure 2 shows the structure of a classic Tower Defense game. A fixed path with enemies can be recognized and towers have already been placed. Each game features its own basic story which determines the names and design of its elements. Some games also offer a multiplayer option, which is omitted in this article. The specific basic story will be explained later in the qualitative analysis for each game as many revenue models are tied to the story of its respective game. 


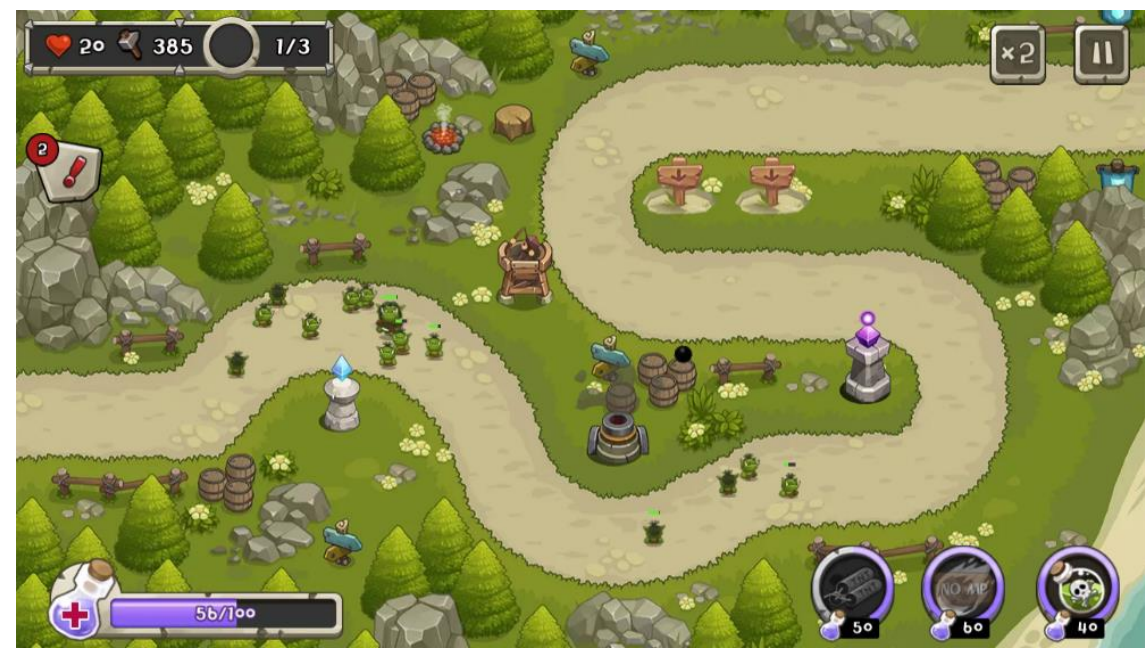

Figure 2: Screenshot of a classic Tower Defense game. Game shown: Tower Defense King https://play.google.com/store/apps/details?id=com.mobirix.towerking (author's own screenshot)

\section{ANALYSIS OF REVENUE MODELS}

The data collection procedure used in this study will be outlined before examining games of the Tower Defense genre. The analysis of the revenue models is based on paid and free apps.

\subsection{Data collection}

The data used for the analysis was collected on Nov. 16th, 2018, partially automated from Google Play. The Tower Defense genre is not a separate category in the store. Therefore, all games suggested by searching the store for "Tower Defense" are considered. The source code of the store page was searched by a script [20]. That way the name, the number of installations, the price, the user rating and the file size could be stored for each game. The website was previously saved in HTML format and searched using the Beautiful Soap [19] framework. The search queries were performed with a German IP address. The data provided by Google Play is already structured as follows:

- Installations: Each app is assigned one of the following categorical values: $10+, 100+,[\ldots], 500.000+,[\ldots]$, 10.000.000+. The exact number of installations cannot be determined directly via Google Play.

- Price: The price is given as an exact value in EUR.

- Rating: The rating scale of Google Play allows ratings in the range of 1 to 5 stars. 5 stars signify rapturous acclaim and one star expresses disappointment. The value given in the dataset indicates the average rating as a floating-point number.

- Size: The size is provided in MB.

\subsection{Complete overview}

Games are generally categorized as paid and free games on Google Play. The survey provided data on 245 games in total. $83 \%$ of these are free and the remaining $17 \%$ are paid. Due to this subdivision the analysis of the business models is also subdivided into the corresponding chapters. The result of this analysis is merely the status quo of the market. The popularity of a revenue model indicates its lucrativeness. Whether the revenue model contributes to a successful business model cannot be conclusively proven, however, due to the other unknown aspects of the business model, such as the development expense involved in releasing the game.

\subsection{Paid apps}

In the Tower Defense games genre $17 \%$ of all games are paid. This is significantly higher than the average proportion of paid apps, which is $4.8 \%$ for Google Play (see [1]). In the "Strategy" category, which is the superordinate category of Tower Defense games, the proportion of paid apps is already $9.7 \%$ (see [1]). Table 1 shows the distribution of paid game installations in relation to the average rating of the respective game. The average price is $2.12 \mathrm{EUR}$. At a median price of 1.99 EUR, the maximum price is 5.99 EUR and the minimum price 0.59 EUR. No data is available on the average price of all apps on Google Play. There are no noticeable differences compared to Apple's Appstore with an average price of USD 2.03 (see [21]). There is a tendency towards a positive correlation between the rating and the number of installations. 
Table 1: Paid games' distribution of installations

\begin{tabular}{c|c|c}
\hline Installations & Number of games & $\begin{array}{c}\text { Average user rating } \\
\text { (on a scale of 1 to 5 points) }\end{array}$ \\
\hline $1.000 .000+$ & 3 & 4,7 \\
$500.000+$ & 5 & 4,72 \\
$100.000+$ & 12 & 4,33 \\
$50.000+$ & 5 & 4,3 \\
$10.000+$ & 5 & 4,45 \\
1.000 & 5 & 4,28 \\
500 & 1 & Not specified \\
100 & 3 & 4,0 \\
\hline
\end{tabular}

It's clearly visible that the revenue model of app sales is becoming interesting for more popular games. It's also noticeable that the three most popular games with 1,000,000 installations were installed significantly less frequently than games that are initially offered free of charge. The nine most popular games which are offered free of charge have been installed over 10,000,000 times. This can be explained by the negative correlation between the price of an app and its popularity (see [17]). The higher the price of an app, the lower the download numbers tend to be.

A minimum revenue can be calculated by looking at the three games with the highest number of installations. Companies have to consider further deductions, however, such as a fee to the marketplace holder, e. g. $30 \%$ of sales for Google Play, and VAT. Since not all revenues are generated out of Germany, different VAT regulations in other countries must be considered. Cross-platform synergies can be used during development if the provider can reuse parts of the game for other platforms. Prices can also be adjusted over time, of course, and different prices may be charged for new versions. Table 2 summarizes the projected minimum revenues for the most popular paid games. These values were calculated by multiplying the minimum number of installations by the price of the app minus the fee for the Appstore. Sales taxes are not considered.

Table 2: Projected minimal revenue for the most popular paid games

\begin{tabular}{c|c|c}
\hline Game & Price (in EUR) & Projected minimal revenue (in EUR) \\
\hline Dungeon Defense & 0,99 & 693.000 \\
Empire Warriors Premium: Tactical TD Game & 0,59 & 413.000 \\
Bloons TD 5 & 3,19 & 2.233 .000 \\
\hline
\end{tabular}

\subsection{Free Apps}

In this chapter the five most popular games of the Tower Defense genre are analyzed regarding their revenue model used. First, the game proper is described. Based on it the revenue model follows. The information is taken directly from the game and its description on Google Play.

\subsubsection{Robo Defense (Free)}

Robo Defense (Free) is a classic Tower Defense game with some small variations. The map is initially open, so towers can be built without local restrictions, and the paths of the opponents adapt to the locations of the towers. Consequently, the goal is to keep the enemies on the map as long as possible by strategically building towers to increase the distance the robots have to travel. In addition, the enemies come from both sides of the map and try to get to the opposite one. The game is based on a robot space scenario but is not linked to a story or a higher goal.

The game is available for free and has no direct revenue model if viewed in isolation. In the free version, however, a small pop-up at the beginning of the game advertises the full version of the game. That's a prime example of the freemium revenue model. The free version features a single map with 11 difficulty levels, whereas the full version offers several maps and an infinite number of upgrades and difficulty levels. The full version has a rating of 4.8 out of 5 points, costs 2.19 EUR, has been installed over 500,000 times and is the fifth most popular paid game of the genre on Google Play. Therefore, Robo Defense (Free) doesn't generate any direct revenue. With more than 10 million installations of the free version, however, it is roughly estimated that the free version convinces every twentieth player to purchase the paid version. In this particular case the freemium revenue model can be regarded as a sensible and obviously very successful choice. For Tower Defense games both app versions can be rather easily distinguished by offering additional maps or tower features in the paid version. 


\subsubsection{Grow Empire: Rome}

Grow Empire: Rome differs from the classic iteration of a Tower Defense game but is still listed among the games of this genre. The game represents a medieval world and offers the possibility to play in two modes: "Defend" and "Attack". In "Defend" mode computer-controlled opponents run to the player's fortress in a straight line and try to break through by hitting it. The opponents arrive in waves at self-paced intervals. The player, on the other hand, can expand his or her fortress and send own units onto the field in order to defeat the hostile ones. In "Attack" mode the player can see a map with possible targets. All settlements around the player's fortress are targets of varying difficulty levels. The further away the settlement is the more difficult it is to conquer. By beating enemy settlements, the player can create colonies and continue fighting until the whole map is conquered. The game does not have a multiplayer option but requires Internet access to play.

Grow Empire: Rome combines the revenue models in-app purchases and in-app advertisement. The game has two separate internal currencies. Gold coins are used for all necessary purchases and jewels allow the purchase of boxes containing Power-Ups. In this case Power-Ups are permanent game advantages, such as a $20 \%$ increase in damage. There is an option to buy jewels in an item shop but no possibility to buy gold coins or exchange them for jewels. After a few attack waves in both modes, ads will be displayed across the screen as videos or images. The game has been installed over 10 million times and has a rating of 4.5 out of 5 points. There are over 1500 attack waves to defeat and over 120 cities to conquer.

\subsubsection{Royal Revolt 2: TowerDefense}

Royal Revolt 2 is a classic Tower Defense game with several expansions. The player is transferred to a medieval world and assigned a forest area including a fortress. Said fortress should be upgraded and paths should be created in the forest area which the enemy units use to reach it. The player can build towers, too. In this game opponents are other humans who challenge the player. It's possible to take one's own units and a significantly stronger "Commander" unit into battle. Besides the actual game, the fortress must be strengthened regularly, and residents have to be provided with food. The game uses an internal currency system for those tasks.

The internal currency system mentioned above comprises several currencies. Besides gold coins and jewels, pearls and bread must be managed. Gold is obtained by defeating enemy units, exchanging it for jewels or in the item shop via in-app purchases. It is used for most of the necessary features such as upgrading the fortress, buying bread and providing units. Jewels can only be purchased through the item shop. Jewels are an extremely powerful currency as they can be exchanged for Power-Ups, such as additional workers, gold, food, more surface area, protection of gold from enemies, and special landscapes that can be created. The other two currencies play a minor role. It is important to note that the item shop also offers a Power-Up subscription. This subscription is available in three levels from 10 to 100 EUR per month. Regular payments can be realized through this special variant of in-app purchases.

\subsubsection{Grow Castle}

Grow Castle is a variation of the classic Tower Defense game. The game features a 2D layout and cartoonish graphics. It's set in a medieval fantasy world with stones and fantasy creatures as opponents. The player has a fortress on the left side of the screen. Waves of enemies appear from the right side of the screen and can be defeated by own units stationed behind the fortress. Additionally, four units can be placed on the fortress and two units next to it. The fortress itself can be upgraded. The player can build a city behind the fortress in order to earn internal currencies. It's also possible to conquer other fortresses. This is achieved by defeating predefined connected waves of enemies. Conquering fortresses offers an internal game advantage through the main currency.

The internal main currency is gold, which is obtained by defeating opponents. Furthermore, gold can be exchanged in an item shop for money or earned by watching advertising videos. Consequently, the revenue models in-app purchases and in-app advertising are used. Figure 3 shows an example of an in-app purchase offer for all the apps considered. It's noticeable that the prices are significantly higher than those of the paid apps proper; and that they are presumably also paid by some players. Figure 4, shown below figure 3, illustrates the option of viewing advertising videos. The pop-up window shown becomes available after winning a battle. The player can acquire a game advantage by watching the advertisement. This is a variation of the in-app advertising revenue model. 


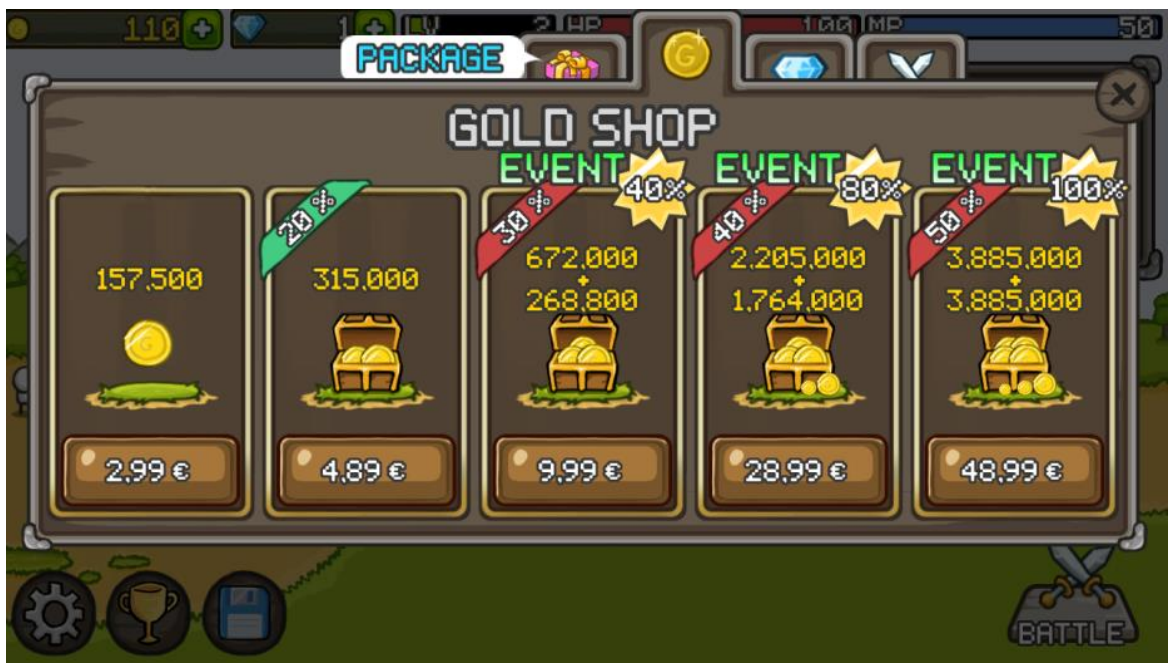

Figure 3: Implementation of the in-app purchases revenue model with the Gold Shop in the game Grow Castle https://play.google.com/store/apps/details?id=com.raongames.growcastle (author's own screenshot)

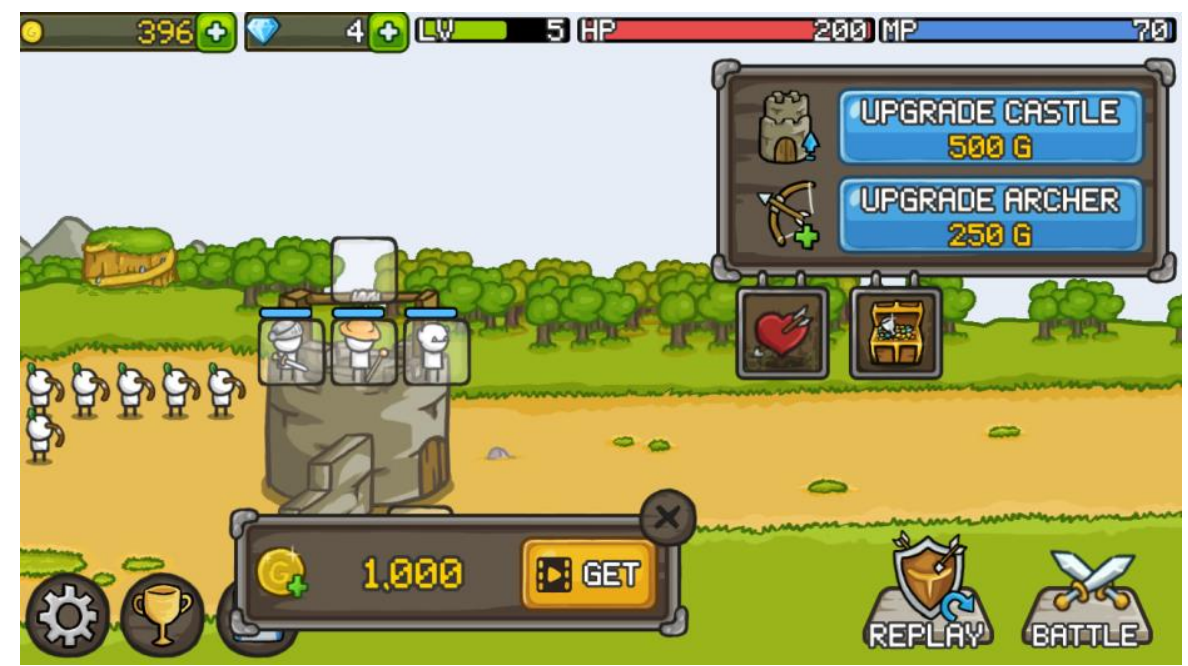

Figure 4: Implementation of the in-app advertisement revenue model in the game Grow Castle. In-game gold can be earned by watching a video. https://play.google.com/store/apps/details?id=com.raongames.growcastle (author's own screenshot)

\subsection{Alien Creeps TD - Epic TowerDefense}

Alien Creeps TD is a classic Tower Defense game. It takes place in space with aliens as enemies and known military weapons as towers. The game's narrative is told in a short story with characters that can be seen on the map. The goal of the game is to fight one's way through all levels. Some levels offer the possibility to spawn units through certain towers on the opponents' paths to fight them. These two features differ from the classic definition of Tower Defense games. Another difference is the "Commander" character. The Commander is present in every game and acts directly on the paths of the enemy units but is still completely controlled by the player. The Commander attacks enemy units as soon as he approaches them. Building fortresses costs energy. Energy units can only be earned by defeating enemy units in a level. The amount of energy units is reset in each level.

Besides the above-mentioned energy there are also gold and diamond currencies in the game. Gold is needed for upgrades and new towers. New towers can be bought in the main menu and used in subsequent levels. In addition to new towers, other Power-Ups, such as one-time attacks that annihilate all enemy units, can be purchased. Diamonds are obtained by clearing levels. They allow the additional purchase of Power-Ups not obtainable with gold. Both internal currencies can be purchased in an item shop. Consequently, the game uses the in-app purchase revenue model. 


\section{CONCLUSION}

A relatively high proportion of paid apps in the genre studied initially indicates that the app sale revenue model is attractive. Even if installations of popular free apps are at least 10 times higher revenues can, obviously, be generated that justify the development, operating and sales expenses.

The five free apps considered, all of which are very widely distributed, use different revenue models. One game utilizes the freemium model. Four out of five games use the in-app purchases revenue model. It's obviously particularly suitable for apps such as games that are used regularly and over extended periods of time by consumers. Two of the five games also use in-app advertising in conjunction with in-app purchases. In-app advertising is, therefore, an accepted addition to in-app purchases.

Two variations of the revenue models defined by Dörndorfer and Seel were identified for the free apps considered. The in-app advertising revenue model was modified in Grow Castle in such a way that in-game advantages can be earned by viewing advertising. This increases the probability of perceiving the advertisement as less annoying. In the game Royal Revolt 2 the in-app purchases revenue model was modified in such a way that the player's purchases are stabilized by a subscription model. This is always useful if the purchased elements can be used up by playing the game. Apparently, profitable niches can be exploited by small variations of these revenue models.

Selecting a revenue model for an app is a complex endeavor. The success associated with a revenue model is not universal but depends on the app's target audience. The revenue model selector provided by [11] can give an initial helpful orientation but needs to be fine-tuned depending on the genre and the competitive environment.

\section{REFERENCES}

[1] 42matters AG: Store Stats for Mobile Apps. 2019, https://42matters.com/stats, Retrieved February 9, 2019

[2] adjust: Mobile Benchmarks 2018. https://www.adjust.com/resources/ebooks/mobile-benchmarks-report-2018, Retrieved February 9, 2019

[3] App Annie: Umsatz mit mobile Apps weltweit in den Jahren 2015 und 2016 sowie eine Prognose für 2017 und 2021 (in Milliarden US-Dollar). 2017, https:/de.statista.com/statistik/daten/studie/550222/umfrage/umsatz-mit-appsweltweit/, Retrieved February 7, 2019

[4] AppBrain: Number of Android Applications. 2019, https://www.appbrain.com/stats, Retrieved February 7, 2019

[5] AppBrain: Free vs. paid Android apps. 2019, https://www.appbrain.com/stats/free-and-paid-android-applications, Retrieved February 7, 2019

[6] App Promo: Apple's App Store had double Google's million dollar publishers in 2018. 2019, http://apppromo.com/apples-app-store-had-double-googles-million-dollar-publishers-in-2018/, Retrieved February 7, 2019

[7] Ariely, D. und Kreisler, J.: Teuer ist relativ. Ullstein, Berlin, 2018

[8] Avery, P.; Togelius, J.; Alistar, E.; van Leeuwen R. P.: Computational intelligence and tower defence games. In: 2011 IEEE Congress of Evolutionary Computation (CEC), New Orleans, LA, 2011, pp.1084-1091

[9] Crussell, J., Stevens, R., Chen, H.: MAdFraud: investigating ad fraud in android applications. In Proceedings of the 12th annual international conference on Mobile systems, applications, and services (MobiSys '14). ACM, New York, NY, USA, 2014, pp.123-134

[10] DaSilva, C. M. und Trkman, P.: Business Model: What It Is and What It Is Not. In: Long Range Planning, Volume 47, Issue 6 (2014), pp.379-389

[11]Dörndorfer, J.: Mobile Revenue Model Catalogue - MRMC, Erlösmodellselektor. oJ, http://mrmc.if.hawlandshut.de/survey, Retrieved February 7, 2019

[12] Dörndorfer, J. und Seel, C.: Mobile Revenue Model Catalogue: A guide through the diversity of mobile revenue models. In: Hofmann, R., Alm, W. (Hrsg): Wissenstransfer in der Wirtschaftsinformatik, Fachgespräch im Rahmen der MKWI 2016. Hochschule Aschaffenburg, Information Management Institut, Aschaffenburg, 2016, pp.10-18

[13]Dörndorfer, J. und Seel, C.: Erlösmodelle von mobilen Anwendungen - Eine Analyse ausgewählter Modelle. In: Barton, T., Herrmann, F., Meister, V. G., Müller, C., Seel, C. (Hrsg.): Prozesse, Technologie, Anwendungen, Systeme und Management 2017: Angewandte Forschung in der Wirtschaftsinformatik. mana-Buch, Heide, 2017, pp. $146-156$

[14] Dörndorfer, J. und Seel, C.: MRMC - Eine Plattform zur Selektion von Erlösmodellen für mobile Anwendungen. In: Barton, T., Herrmann, F., Meister, V. G., Müller, C., Seel, C., Steffens, U. (Hrsg.): Angewandte Forschung in der Wirtschaftsinformatik. mana Buch, Heide, 2018, pp.254-263

[15] Gassmann, O., Frankenberger, K., Csik, M.: Geschäftsmodelle entwickeln, 55 innovative Konzepte mit dem St. Galler Business Model Navigator. 2. Aufl., Hanser, München, 2017

[16] Ghazawneh, A. und Mansour, O.: Value Creation in Digital Application Marketplaces: A Developers' Perspective. In: Association for Information Systems (Hrsg.): International Conference on Information Systems (ICIS 2015): Exploring the Information Frontier, Fort Worth, Texas, USA, 2015, pp.1258-1274

[17] Jansen S., Bloemendal E.: Defining App Stores: The Role of Curated Marketplaces in Software Ecosystems. In: Herzwurm G., Margaria T. (Hrsg.): Software Business, From Physical Products to Software Services and Solutions. 
ICSOB 2013. Lecture Notes in Business Information Processing, vol 150. Springer, Berlin, Heidelberg, 2013, pp. 195-206

[18] Osterwalder, A., Pigneur, Y.: Business Model Generation: A Handbook for Visionaries, Game Changers, and Challengers. John Wiley \& Sons, Hoboken, New Jersey, 2010

[19] Richardson, L.: Beautiful Soap. oJ, https://www.crummy.com/software/BeautifulSoup/, Retrieved February 9, 2019

[20] Schäfer, T.: Skript PlayStoreScraper. 2018, https://github.com/1610337/PlayStoreScraper, Retrieved February 9 , 2019

[21] Trefis.com: Schätzung des durchschnittlichen Preises kostenpflichtiger Apps für das iPhone und iPad weltweit in den Jahren 2009 bis 2023 (in US-Dollar). 2017, https://de.statista.com/statistik/daten/studie/ 170003/umfrage/ preisentwicklung-von-apps-in-den-fuehrenden-app-stores-weltweit/, Retrieved February 7, 2019 